\title{
Fuzzy Inference System to Control PC Power Failures
}

\author{
V.Mary Sumalatha \\ D.I.E.T College \\ Anakapalle, Andhra Pradesh \\ India
}

\author{
K.V.Ramani \\ D.I.E.T College \\ Anakapalle, Andhra Pradesh \\ India
}

\author{
K.V.Lakshmi \\ D.I.E.T College \\ Anakapalle, Andhra Pradesh \\ India
}

\begin{abstract}
If there is any one component that is absolutely vital to the operation of a computer, it is the power supply. Without it, a computer is just an inert box full of plastic and metal. The power supply converts the alternating current line to the direct current needed by the personal computer. This paper presents an application of fuzzy logic to control power failures in personal computers. The application uses fuzzy sets, fuzzy if-then rules and fuzzy inference system. Fuzzy logic is widely used to solve uncertain problems. Fuzzy inference systems (FIS) are widely used for process simulation or control. They can be designed either from expert knowledge or from data. For complex systems, FIS based on expert knowledge only may suffer from a loss of accuracy. This is the main incentive for using fuzzy rules inferred from data.
\end{abstract}

\section{Keywords}

Fuzzy sets, Fuzzy if-then rules, Fuzzy logic, Fuzzy inference systems, Mamdani Fuzzy modeling.

\section{INTRODUCTION}

Electronically controlled equipment is frequently prone to failures due to the disturbances caused in electrical power. They cause harm to industries, commercial and residential people. Blackout, brownout, sag, spike and swing are some examples of disturbances related to power supply problems. The disturbance caused by power may be accidental or incidental. Some problems may be due to voltage fluctuations, lightning, thunderstorms, poor wiring, grounding problems, load variations etc. To analyze the voltage fluctuations in a personal computer it is important to consider the components that can be affected due to power failures. These real uncertainities make hard the decision task of forecasting the success or failure of computer based loads against possible power quality related problems. There for fuzzy logic[4][9][10] is the appropriate solution to represent load sensitivity to voltage fluctuations. Most of the power problems are due to the susceptibility of current loads with present power systems [8] normal operations.[3]

This paper is divided into six sections. Section 2 presents fundamentals of fuzzy logic. The voltage, current problems are discussed in Section 3. Mathematical modeling is presented in Section 4. Experiment, results are presented in Section 5, conclusion is given in Section 6.

\section{FUNDAMENTALS OF FUZZY LOGIC}

Fuzzy logic is introduced by Professor Lotif Zadeh in 1973. Fuzzy logic is a problem solving control system methodology that lends itself to implementation in systems ranging from simple, small, embedded micro-controllers to large networked multichannel PC or workstation-based data acquisition and control system. It can be implemented in hardware, software or combination of both. Fuzzy logic's approach to control problems mimics how a person would make decisions, only much faster. The Fuzzy logic is different from conventional control methods. The Fuzzy logic model is empirically-based, relying on an operators experience rather than their technical understanding of the system.

The Fuzzy logic technique is based on four basic concepts.

- Fuzzy set

- Linguistic variable

- Possibility distributions

- Fuzzy if-then rules

The first three concepts are fundamental for all sub areas in fuzzy logic. The fourth concept is also important because it is the basis for most industrial applications of fuzzy logic developed to date including many fuzzy logic control systems.

\subsection{Fuzzy set:}

Fuzzy set is a set with a smooth boundary. Fuzzy set theory generalizes classical set theory to allow partial membership. The best way to introduce fuzzy sets is to start with a limitation of classical sets. A set in classical set theory always has a sharp boundary because membership in a set is a black and white concept -an object either completely belongs to the set or does not belong to the set all. A fuzzy set is defined by a function that maps objects in a domain of concern to the membership value in the set. That function is called membership function and usually denoted by the Greek symbol $\boldsymbol{\mu}$ for ease of recognition and consistency.

Types of membership functions:

1) Triangular Membership Function

2) Trapezoidal Membership Function

3) Gaussian Membership Function

4) Bell-Shaped Membership Function

5) Sigmoidal Membership Function

6) S Membership Function

7) П Membership Function 


\subsection{Linguistic variables}

A fuzzy set can be used to describe the value of a variable. A Linguistic variable enables its value to be described both qualitatively by a linguistic term i.e. a symbol serving as the name of a fuzzy set and quantitatively by corresponding membership function which expresses the meaning of fuzzy set, The linguistic term is used to express concepts and knowledge in human communication, where as membership function is useful for processing numeric input data.

Examples: Temperature Displacement, Velocity, Flow, Pressure, Power.

\subsection{Possibility Distributions}

Assigning a fuzzy set to a linguistic variable constraints the value of the variable .Example: Suppose the police report that the suspect of a bombing is a terrorist between 20 and 30 years old. This can be expressed as

$$
\text { Age }(\text { suspect })=[20,30]
$$

It states that the suspects age can be $20,21,22, \ldots . .29$ or 30 .It is impossible for the suspect to be 19,31 or any other age not included in the set $[20,30]$.The above assignment introduce a sharp boundary between possible and impossible value.

\subsection{Fuzzy if-then Rules}

A knowledge representation scheme for describing a functional mapping or a logic formula that generalizes an implication in two valued logic. This is achieved by using linguistic variable to describe elastic conditions in the "If part" of fuzzy rules.

There are two types of fuzzy rules:

- Fuzzy mapping rules

- Fuzzy Implication rules

A fuzzy mapping rule describes a function mapping relationship between inputs and outputs using linguistic terms, while fuzzy implication rule describes a generalized logic implication relationship between two logic formulas involving linguistic variables and imprecise linguistic terms. Fuzzy If-Then rules have been applied to many disciplines such as control systems, decision making, pattern recognition and system modeling. These are also critical role in industrial applications ranging from consumer products, robotics, manufacturing, process control, medical imaging, and financial trading.

\subsection{Structure of Fuzzy rules}

A fuzzy rule is the basic unit for capturing knowledge in many fuzzy systems. A fuzzy rule has two components.

- If-part(Also referred to as the antecedent)

- Then-part(Also referred to as the consequent)

- $\quad \mathrm{IF}<$ antecedent $>\mathrm{THEN}<$ consequent $>$

\subsection{Fuzzy Inference System}

Fuzzy inference is the process of formulating the mapping from a given input to an output using fuzzy logic. The mapping then provides a basis from which decisions can be made, or patterns discerned. The process of fuzzy inference involves all of the pieces that are described in the previous sections: Membership
Functions, Logical Operations, and If-Then Rules. You can implement two types of fuzzy inference systems in the toolbox: Mamdani-type[5][6] and Sugeno-type[7]. These two types of inference systems vary somewhat in the way outputs are determined.

Fuzzy inference systems (FIS) are one of the most famous applications of fuzzy logic and fuzzy sets theory [1]. They can be helpful to achieve classification tasks, offline process simulation and diagnosis, online decision support tools and process control. The strength of FIS relies on their twofold identity. On the one hand, they are able to handle linguistic concepts. On the other hand, they are universal approximates able to perform nonlinear mappings between inputs and outputs. These two characteristics have been used to design two kinds of FIS. The first kind of FIS to appear focused on the ability of fuzzy logic to model natural language [2]. These FIS contain fuzzy rules built from expert knowledge and they are called fuzzy expert systems or fuzzy controllers, depending on their final use. Prior to FIS, expert knowledge was already used to build expert systems for simulation purposes. These expert systems were based on classical Boolean logic and were not well suited to managing the progressiveness in the underlying process phenomena. Fuzzy logic allows gradual rules to be introduced into expert knowledge based simulators. It also points out the limitations of human knowledge, particularly the difficulties in formalizing interactions in complex processes.

\subsection{Overview of Fuzzy Inference Process}

Fuzzy inference process comprises of five parts: Fuzzification of the input variables, application of the fuzzy operator (AND or $\mathrm{OR}$ ) in the antecedent, implication from the antecedent to the consequent, aggregation of the consequents across the rules, and defuzzification.

\subsubsection{Fuzzify Inputs}

The first step is to take the inputs and determine the degree to which they belong to each of the appropriate fuzzy sets via membership functions.

\subsubsection{Apply Fuzzy Operator}

After the inputs are fuzzified, you know the degree to which each part of the antecedent is satisfied for each rule. If the antecedent of a given rule has more than one part, the fuzzy operator is applied to obtain one number that represents the result of the antecedent for that rule.

\subsubsection{Apply Implication Method}

Before applying the implication method, you must determine the rule's weight. Every rule has a weight (a number between 0 and 1), which is applied to the number given by the antecedent.

After proper weighting has been assigned to each rule, the implication method is implemented. A consequent is a fuzzy set represented by a membership function, which weights appropriately the linguistic characteristics that are attributed to it. 


\subsubsection{Aggregate All Outputs}

Because decisions are based on the testing of all of the rules in a FIS, the rules must be combined in some manner in order to make a decision. Aggregation is the process by which the fuzzy sets that represent the outputs of each rule are combined into a single fuzzy set.

\subsubsection{Defuzzify}

The input for the defuzzification process is a fuzzy set (the aggregate output fuzzy set) and the output is a single number.

\subsection{Fuzzy Logic Toolbox}

- Fuzzy Inference System (FIS) Editor to handle the highlevel issues for the system-How many input and output variables? What are their names?

- Membership Function Editor to define the shapes of all the membership functions associated with each variable

- Rule Editor to edit the list of rules that defines the behaviour of the system.

- Rule Viewer to view the fuzzy inference diagram. Use this viewer as a diagnostic to see, for example, which rules are active, or how individual membership function shapes influence the results

- Surface Viewer to view the dependency of one of the outputs on any one or two of the inputs-that is, it generates and plots an output surface map for the system.

\section{POWER PROBLEMS IN PERSONAL COMPUTERS}

In a personal computer, the power supply is the metal box usually found in a corner of the case. The power supply is visible from the back of many systems because it contains the power-cord receptacle and the cooling fan. Power supplies, often referred to as "switching power supplies", use switcher technology to convert the AC input to lower DC voltages. The typical voltages supplied are:

$$
\begin{array}{ll}
\text { - } & 3.3 \text { volts } \\
\text { - } & 5 \text { volts } \\
\text { } & 12 \text { volts }
\end{array}
$$

The $3.3 \& 5$-volts are typically used by digital circuits, while the 12 -volt is used to run motors in disk drives and fans. The main specification of a power supply is in watts. Watt is the product of the voltage in volts and the current in amperes or amps. Now days the operating system can send a signal to the power supply to tell it to turn off. The push button sends a 5-volt signal to the power supply to tell it when to turn on. The power supply also has a circuit that supplies 5volts, called VSB for "standby voltage" even when it is officially "off", so that the button will work. The three most basic units in electricity are voltage(V), current(I) and resistance(r). Voltage is measured in volts, current is measured in amps and resistance is measured in ohms.

\subsection{Illustration of voltage,current \&resistance}

Consider a system of plumbing pipes. The voltage is equivalent to the water pressure, the current is equivalent to the flow rate, and the resistance is like the pipe size. There is a basic equation in electrical engineering that states how the three terms relate. It says that the current is equal to the voltage divided by the resistance.

Voltage $=$ Current $x$ Resistance $\rightarrow\left[\mathrm{V}=\mathrm{I}^{*} \mathrm{R}\right]$

Power $=$ Voltage $\times$ Current $\rightarrow[\mathrm{P}=\mathrm{VI}]$

And

Power $=$ Current squared $\mathrm{x}$ Resistance $\rightarrow\left[\mathrm{P}=\mathrm{I}^{*} \mathrm{I}^{*} \mathrm{R}\right]$

$\mathrm{P}=\left(\mathrm{V}^{\wedge} 2\right) / \mathrm{R}=\left(\mathrm{I}^{\wedge} 2\right)^{*} \mathrm{R}=\mathrm{V} * \mathrm{I}$

where $\mathrm{V}=$ voltage or potential difference across the resistance $\mathrm{R}$ and $\mathrm{I}$ is the current. Power decreases on increasing the resistance and vice versa. The power is inversely proportional to the resistance

\subsection{Problems in Power Supply}

Power supply in a system is failing needs troubleshooting. Troubleshooting the power supply basically means isolating the supply as the cause of problems within a system and, if necessary, replacing it. The following is a list of PC problems that often are related to the power supply:

- Any power-on or system start up failures or lockups

- Spontaneous rebooting or intermittent lockups during normal operation

- Intermittent parity check or other memory-type errors

- Hard disk and fan simultaneously failing to spin (no $+12 \mathrm{~V}$ )

- Overheating due to fan failure

- Small brownouts that cause the system to reset

- Electric shocks felt on the system case or connectors

- Slight static discharges that disrupt system operation

- $\quad$ Erratic recognition of bus-powered USB peripherals

The following are some symptoms point right to the power supply as a possible cause of failure

- System that is completely dead

- Smoke

- Blown circuit breakers

Power supplies should stay within operating specifications and continue to run a system even if any of these power line disturbances occur:

- Voltage drop to $80 \mathrm{~V}$ for up to 2 seconds

- Voltage drop to 70V for up to .5 seconds

- Voltage surge of up to $143 \mathrm{~V}$ for up to 1 second

\subsection{Primary Function and Operation of power in a personal computer}

The basic function of the power supply is to convert the type of electrical power available to the type the computer circuitry can use. The power supply in a conventional desktop system is designed to convert 120 -volt or $240 \mathrm{~V}$ power into $+3.3 \mathrm{~V},+5 \mathrm{~V}$, and +12 V Direct Current power.

\subsubsection{Positive DC Voltages}

Usually, the digital electronic components and circuits in the system like motherboard, adapter cards, and disk drive logic boards, use the $+3.3 \mathrm{~V}$ or $+5 \mathrm{~V}$ power, and the motors like disk drive motors and any fans use the $+12 \mathrm{~V}$ power. The following is the list of devices and their power consumptions. 


\subsubsection{Power Consumption Ratings for PC Devices}

Voltage Devices Powered

\begin{tabular}{|l|l|}
\hline$+3.3 \mathrm{~V}$ & Chipsets,DIMMs,PCI/AGP cards, miscellaneous chips \\
\hline$+5 \mathrm{~V}$ & $\begin{array}{l}\text { Disk drive logic, SIMMs, PCI/AGP cards, ISA cards, } \\
\text { voltage regulators, miscellaneous chips }\end{array}$ \\
\hline$+12 \mathrm{~V}$ & Motors, voltage regulators (high output) \\
\hline
\end{tabular}

\subsubsection{Negative DC Voltages}

The power supply generates not only $+3.3 \mathrm{~V},+5 \mathrm{~V}$, and $+12 \mathrm{~V}$, but also $-5 \mathrm{~V}$ and $-12 \mathrm{~V}$. normally the positive voltages are everything in the system, the negative voltage $-5 \mathrm{~V}$ is simply routed to the ISA bus on pin B5 so any ISA cards can use it. The motherboard logic typically doesn't use $-12 \mathrm{~V}$ either; however, it might be used in some board designs for serial port or LAN circuits. Although older serial port circuits used $+/-12 \mathrm{~V}$ outputs, today most run only on $+3.3 \mathrm{~V}$ or $+5 \mathrm{~V}$.

The main function of the $+12 \mathrm{~V}$ power is to run disk drive motors as well as the higher-output processor voltage regulators in some of the newer boards. Usually, a large amount of $+12 \mathrm{~V}$ current is available from the power supply, especially in those designed for systems with a large number of drive bays. Besides disk drive motors and newer CPU voltage regulators, the $+12 \mathrm{~V}$ supply is used by any cooling fans in the system - which, of course, should always be running. A single cooling fan can draw between $100 \mathrm{~mA}$ and $250 \mathrm{~mA}(0.1-0.25$ amps); however, most newer fans use the lower $100 \mathrm{~mA}$. The following is the power output rating in non ATX system.

Table 1. Typical Non-ATX Power Supply Output Ratings

\begin{tabular}{|c|c|c|c|c|c|c|c|}
\hline \multirow{2}{*}{$\begin{array}{c}\text { output } \\
\text { (Watts) }\end{array}$} & \multicolumn{700}{|c|}{ Watts } \\
\cline { 2 - 8 }$+5 \mathrm{~V}$ & 10.0 & 15.0 & 20.0 & 25.0 & 32.0 & 35.0 & 45.0 \\
\hline$+12 \mathrm{~V}$ & 3.5 & 5.5 & 8.0 & 10.0 & 10.0 & 13.0 & 15.0 \\
\hline$-5 \mathrm{~V}$ & 0.3 & 0.3 & 0.3 & 0.5 & 0.5 & 0.5 & 1.0 \\
\hline$-12 \mathrm{~V}$ & 0.3 & 0.3 & 0.3 & 0.5 & 0.5 & 0.5 & 1.0 \\
\hline $\begin{array}{c}\text { Calc. } \\
\text { output } \\
\text { (watts) }\end{array}$ & 92 & 141 & 196 & 245 & 280 & 331 & 405 \\
\hline
\end{tabular}

Table 2. Typical ATX Power Supply Output Ratings

\begin{tabular}{|c|c|c|c|c|c|c|c|c|}
\hline \multirow{2}{*}{ output } & \multicolumn{8}{|c|}{ Watts } \\
\hline & 235 & 250 & 275 & 300 & 350 & 400 & 425 & 510 \\
\hline$+3.3 \mathrm{~V}$ & 13 & 13 & 14 & 14 & 28 & 40 & 40 & 30 \\
\hline$+5 \mathrm{~V}$ & 22 & 25 & 30 & 30 & 32 & 40 & 40 & 40 \\
\hline$+12 \mathrm{~V}$ & 8 & 10 & 10 & 12 & 15 & 15 & 15 & 34 \\
\hline$-5 \mathrm{~V}$ & 0.3 & 0.3 & 0.3 & 0.3 & 0.3 & 0.3 & 0.3 & 0.3 \\
\hline$-12 \mathrm{~V}$ & 0.5 & 0.5 & 1.0 & 1.0 & 0.8 & 1.0 & 1.0 & 2.0 \\
\hline$+5 \mathrm{VSB}$ & 2.0 & 2.0 & 2.0 & 2.0 & 2.0 & 2.0 & 2.0 & 3.0 \\
\hline \multicolumn{9}{|c|}{ Total watts $(3.3+5+12)$} \\
\hline & 249 & 288 & 316 & 340 & 432 & 512 & 512 & 707 \\
\hline \multicolumn{9}{|c|}{ Total watts $+3.3 \mathrm{~V}$ and $+5 \mathrm{~V}$ Max. } \\
\hline & 125 & 150 & 150 & 150 & 215 & 300 & 300 & 300 \\
\hline
\end{tabular}

\subsubsection{Components that can be affected by power supply failure}

- Central processing unit (CPU)

- Memory

- $\quad$ Random-access memory (RAM)

- $\quad$ Read-only memory (ROM)

- Basic input/output system (BIOS)

- Caching

- Virtual memory

- Flash memory

- Motherboard

- Power supply

- Hard disk

- Operating system

- Integrated Drive Electronics (IDE) Controller

- Accelerated Graphics Port (AGP)

- Sound card

- Graphics card

- Ports

- Real-time clock

- Fans, heat sinks and cooling systems

- Complementary Metal-oxide Semiconductor

\subsubsection{Types of electrical problem}

An interruption in power or even a slight change in the character of the electricity [9], however brief, can lead to either critical problems or an irritating assortment of intermittent computer malfunctions. There are several types of power problems:

- A blackout is a total power loss and a brownout is a voltage drop, usually evidenced by a sudden dimming of lights.

- A spike is a sudden surge of line voltage, usually caused by a malfunction at the power utility. However, a nearby lightning strike also can cause a spike and can melt electrical and electronic components.

- Voltage swings are intermittent variations of the voltage level on electrical lines. They often occur in industrial parks where heavy electrical equipment is cycled on and off and in older office buildings with inadequate wiring.

\subsubsection{Computer Power Supply Failure Symptoms}

Power supplies are essential hardware components that draw energy from an electrical outlet and convert it into electricity at the proper voltages to power a computer's motherboard and other devices. Power supplies can become overstressed if the system demands more power than the supply is able to put out, which can result in power supply failure. Fortunately, there are a number of telltale signs that can help identify power supply failure.

\section{A. Crashes}

The first tip-off that your power supply is failing is likely to be unexplained computer crashes or restarts. When the motherboard, processor and RAM receive too little power, they experience errors that lead to crashing. The main problem with diagnosing power supply failure as an issue after crashes is that many other computer errors can lead to crashes. Viruses, 
processor overheating, RAM issues and software driver problems can all result in crashes.

\section{B. Heat}

Another important symptom of computer power supply failure is excessive heat coming from the power supply. Power supplies are usually warm to the touch when operating normally but won't be so hot that they're uncomfortable or burn the skin. If your computer crashes, touch the power supply or the part of the case where the power supply is located during operating to see how hot it feels. If it's very hot, there's a good chance the crash was caused by a power supply failure. Another issue with heat is that as the power supply fails, internal fans run slower. This raises the CPU and RAM temperature, which can also lead to crashing.

\section{Noise and Smell}

Noise and smell can indicate power supply failure. When a power supply is severely overstressed, it may become so hot that components inside it burn. If you smell smoke or burning coming from your computer, there's a good chance the power supply is burning out. Noise can also be a key indicator, as power supplies contain cooling fans that often become noisier or groan when the device is failing. Cooling fans within the computer case may also be noisier when the power supply is failing.

\section{Start-up Failure}

If a power supply has suffered total failure, the computer will not be able to start up. In addition, any peripheral devices will not receive power, so no hard drives or fans will spin up. Because motherboard issues can also cause start up failure, it's useful to open a computer and check whether any lights on the motherboard turn on when you attempt to start up. If the motherboard isn't receiving power, chances are the power supply has died.

\section{E. Over heating}

Power supplies should be replaced before they reach failure to protect the system's other components from possible damage due to crashes, lack of power and overheating. Most manufactured computer systems come with a power supply adequate to run the system's basic devices. But when upgrades are added such as new video cards, RAM or extra hard drives, the energy demands may exceed the output of a base line power supply. Whenever you make a substantial hardware upgrade, consider whether a power supply upgrade would be wise in order to provide extra power for the new device.

\section{MATHEMATICAL MODELING}

\subsection{Voltage and current load control using fuzzy logic}

Because most of the power quality problems are related to voltage sags, the voltage limits between 180 to 260 volts are used in this application. To control the voltage, current load and resistance the application is linguistically represented as follows.
1. If the voltage is normal and the current load has no effect then the resistance is normal and pc power will always succeed.

2. If voltage is low and current load is normal then resistance is increased to avoid pc power failure.

3. If voltage is high and current load is normal then resistance is adjusted to avoid pc power failure.

So to maintain a normal power supply in all above cases we need to control the current load accordingly to the voltage fluctuations.

We need to control the voltage and current load to maintain the resistance for the normal power flow in the personal computer. Iin all the cases the personal computer runs without any disturbance in the presence of voltage fluctuations.

Let the input status words for the input voltage, current load and the output variable resistance be:

- Negative High

- Negative Low

- Zero

- Positive Low

- $\quad$ Positive High voltage

- The rules are defined as follows

Table 3. Rules.

\begin{tabular}{|c|l|c|c|c|c|c|}
\hline \multirow{3}{*}{} & \multicolumn{7}{|c|}{ Voltage } \\
\cline { 2 - 7 } & $\begin{array}{l}\text { Neg. } \\
\text { High }\end{array}$ & $\begin{array}{l}\text { Neg. } \\
\text { Low }\end{array}$ & Zero & $\begin{array}{l}\text { Pos. } \\
\text { Low }\end{array}$ & $\begin{array}{l}\text { Pos. } \\
\text { High }\end{array}$ \\
\cline { 2 - 7 } & Pos. High & NH & NH & NH & NL & Z \\
\cline { 2 - 7 } & Pos. Low & NH & NH & NL & Z & PL \\
\cline { 2 - 7 } & Zero & NH & NL & Z & PL & PH \\
\cline { 2 - 7 } & Neg. Low & NL & Z & PL & PH & PH \\
\cline { 2 - 8 } & Neg. High & Z & PL & PH & PH & PH \\
\hline \multicolumn{7}{|c|}{ Resistance } \\
\hline
\end{tabular}

The triangular membership function for voltage, current and resistance is represented in the following graphs. The membership functions are defined for the input variable voltage is presented in Figure 1as follows.

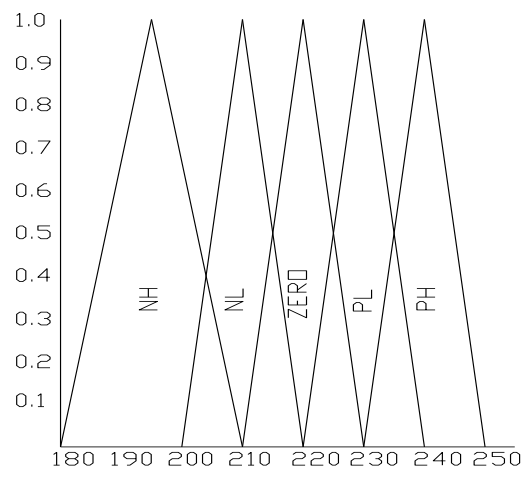

Fig. 1 Input voltage Membership Function.

Membership functions are defined for the input variable current is presented in Figure 2 as follows. 


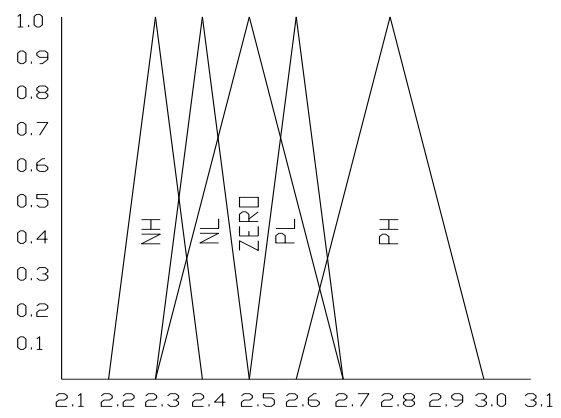

Fig. 2 Input current Membership Function.

Membership functions defined for the output variable resistance is presented in Figure 3 as follows.

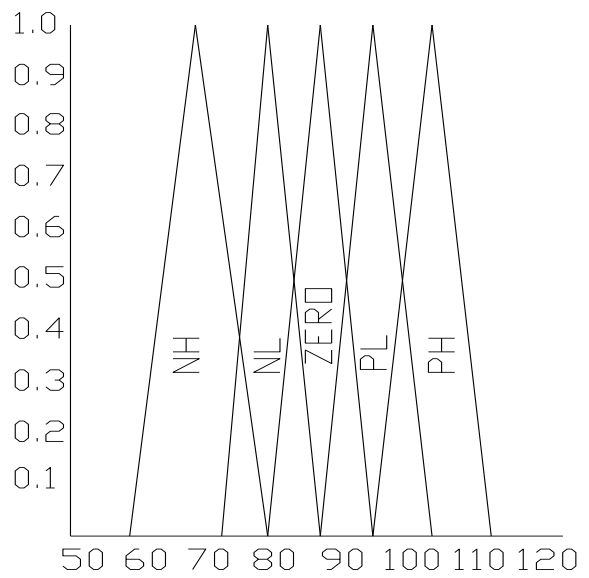

Fig. 3 Output Membership Function.

Suppose the voltage increases from the set point to 222 . It is represented in Figure4 as follows in the membership function.

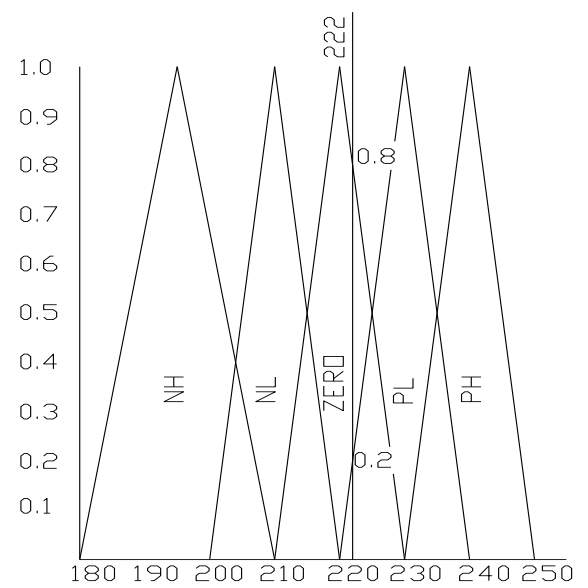

Fig. 4 Change of voltage from 220 to 222
Suppose the current decreases from the set point to 2.44 . It is represented in Figure 5 as follows in the membership function.

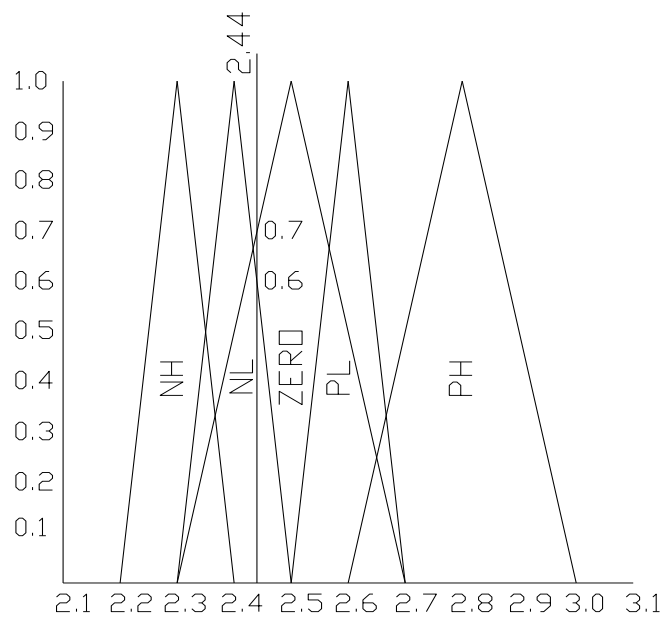

Fig. 5 Change of current to 2.44

The change in voltage and current results in firing of the following rules.

1. If voltage is zero and current is zero then resistance is zero.

2. If voltage is zero and current is Neg. Low then resistance is Pos. Low.

3. If voltage is Pos. Low and current is zero then resistance is Pos. Low.

4. If voltage is Pos. Low and current is Neg. Low then resistance is Pos. High.

To find the resistance we substitute the intersection points in the following formula.

$$
f(x)=\frac{\sum_{i=1}^{N} Z_{j=1} \Pi_{j} \mu_{i j}\left(x_{j}\right)}{\sum_{i=1}^{N} \prod_{j=1}^{N} \mu_{i j}\left(x_{j}\right)}
$$

Resistance is now calculated as

$$
\text { "Zero"x } \mu_{33} \text { "Pos.Low" x } \mu_{23}+\text { "Pos.Low" } \mathrm{x}
$$

Resistance $=\mu_{34}+$ "Pos.High" $\mathrm{x} \mu_{24}$

$$
\begin{aligned}
& \mu_{33}=0.8 \times 0.2=0.48 \\
& \mu_{23}=0.8 \times 0.7=0.56 \\
& \mu_{34}=0.2 \times 0.6=0.12 \\
& \mu_{24}=0.2 \times 0.7=0.14
\end{aligned}
$$$$
\mu_{33+} \mu_{23+} \mu_{34+} \mu_{24}
$$

Resistance is 942

\section{EXPERIMENTAL RESULTS}

The application is implemented in Mat lab using fuzzy logic tool box [8]is represented in Figure 6 as follows. 


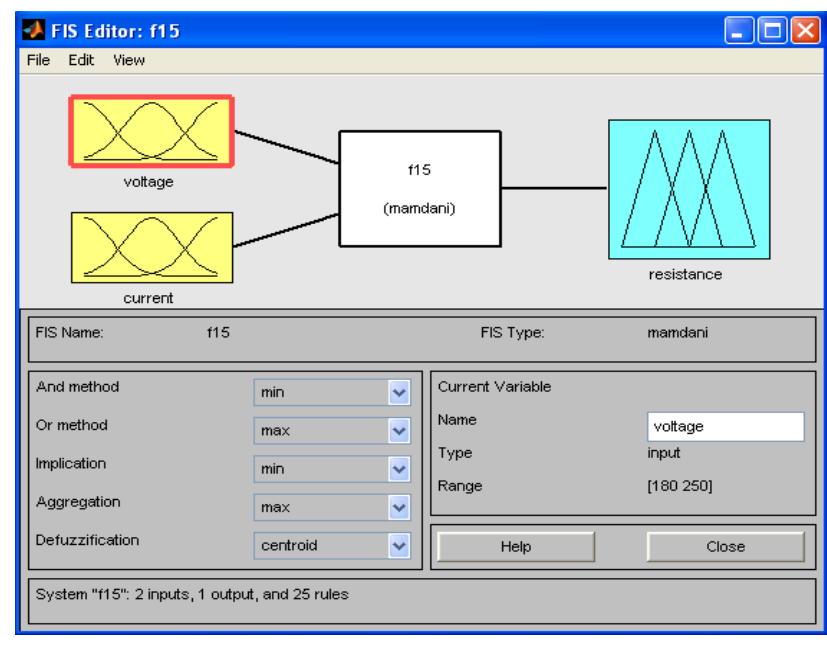

Fig. 6 Fuzzy Inference System

Appropriate membership functions are defined for input and output in Figure 7,8 and 9:

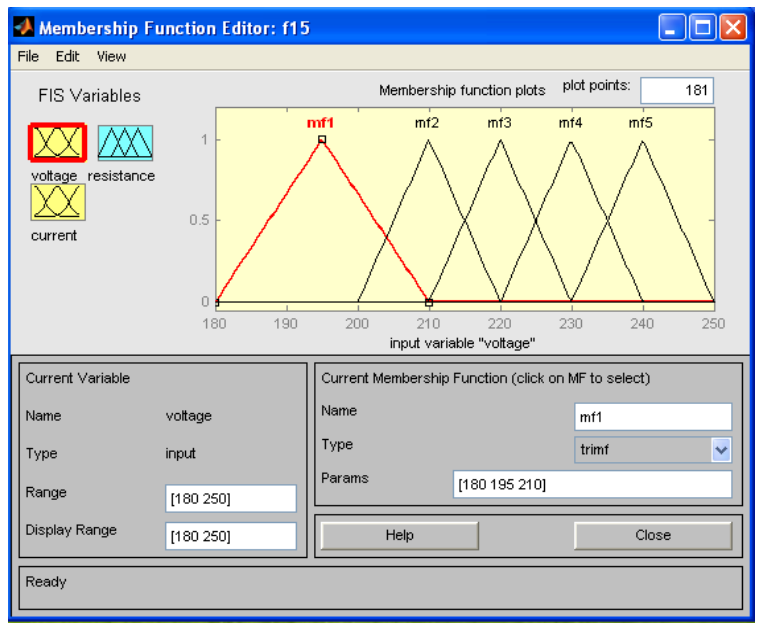

Fig. 7 Input Membership Function for voltage

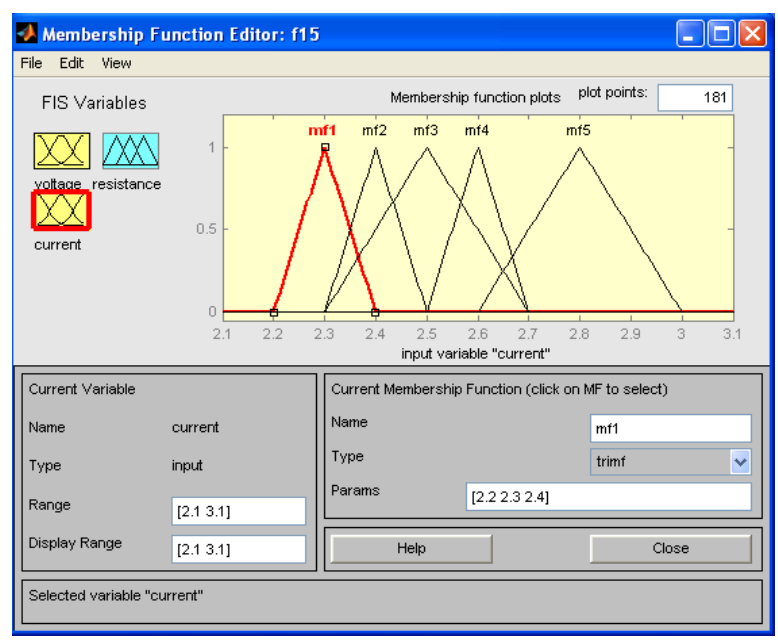

Fig. 8 Input Membership Function for current load

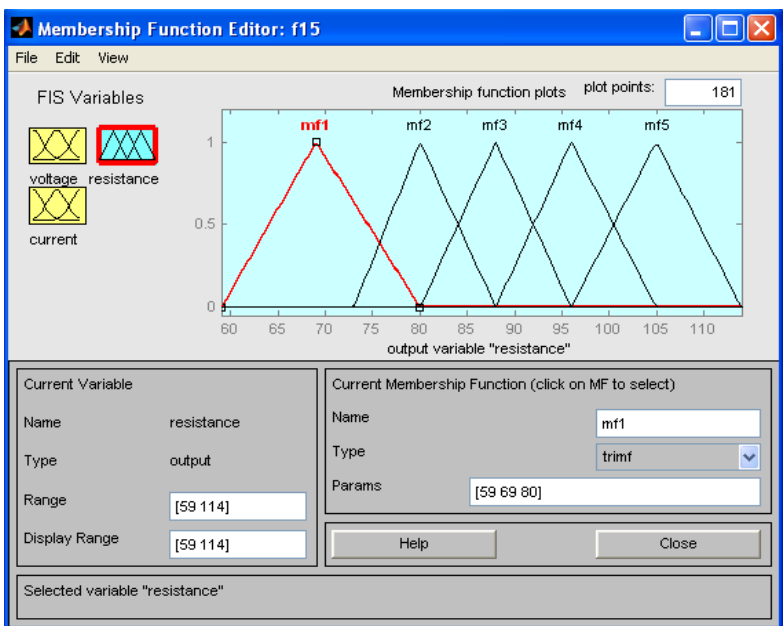

Fig. 9 Output Membership Function for resistance

Now the rules are defined in Figure 10.

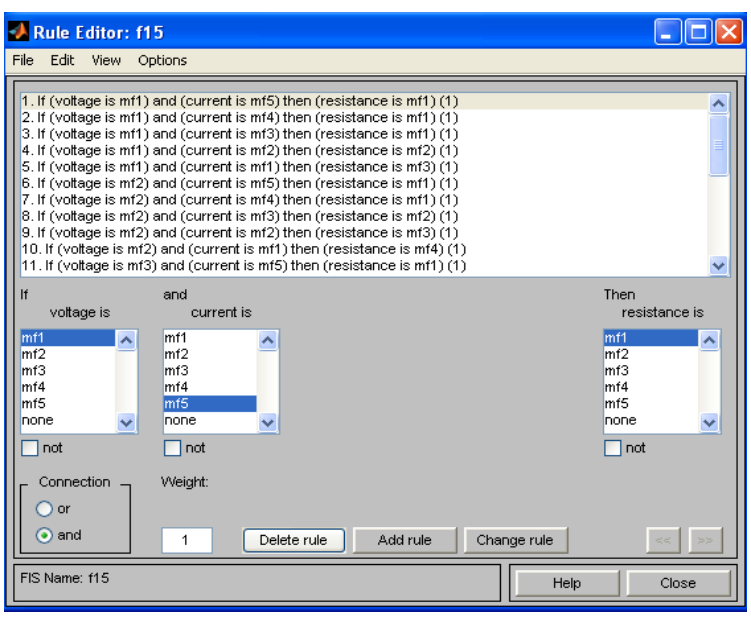

Fig. 10 Rule Editor

The rule viewer id presented in Figure 11.

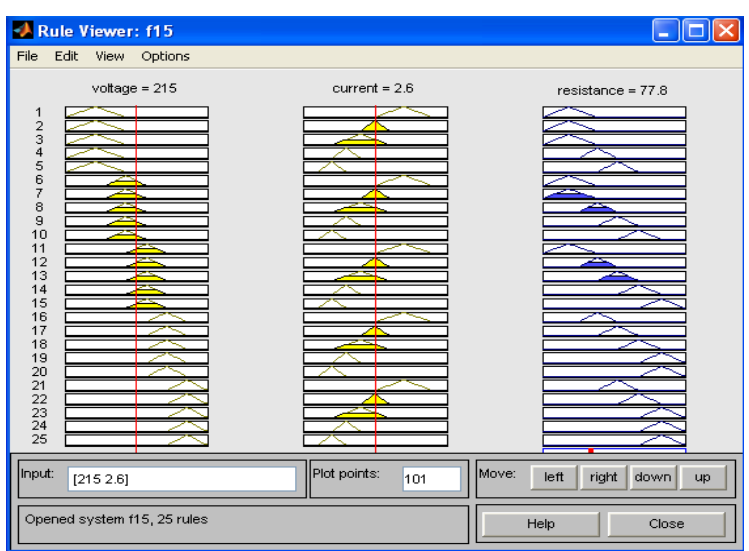

Fig. 11 Rule Viewer 
The surface viewer is presented in Figure 12.

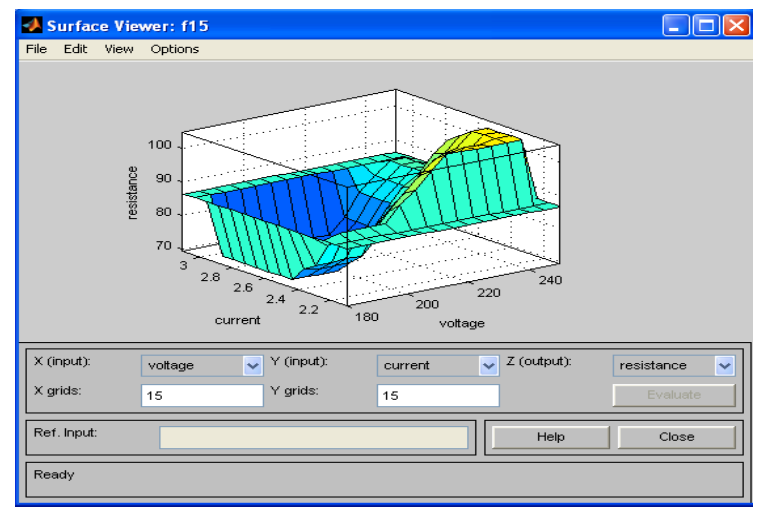

Fig. 12 Surface Viewer

The output is presented in Figure 13.The output for the voltage 222 , current load is 2.44 and the resistance is calculated as 94.2465 which is the value calculated in the mathematical modeling.

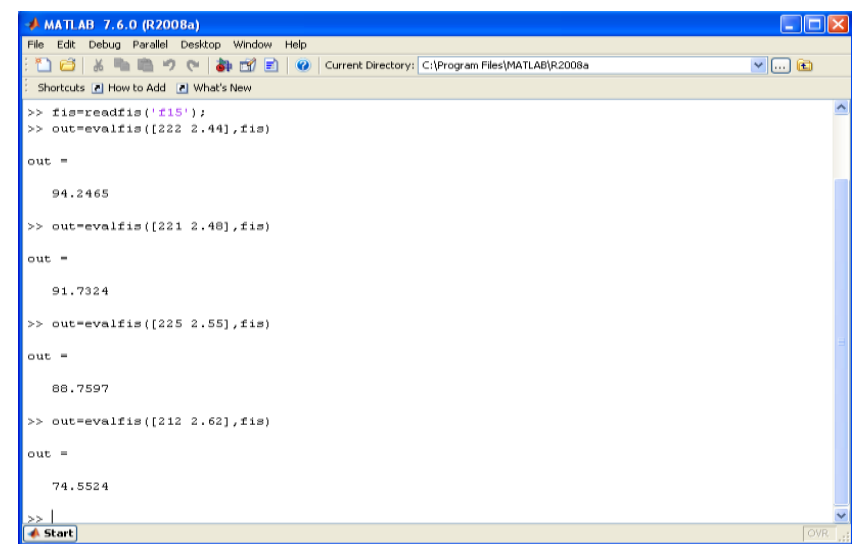

Fig.13. Output of the Application.

\section{CONCLUSION}

This paper has presented an application of fuzzy logic in power failures. The uncertainty in power failures was formulated by fuzzy logic theory through membership functions, which usually do not use strict boundaries, and such a feature was found suitable in dealing with the vagueness associated with the power failure system. The results presented show the potential of intelligent system techniques for diagnosing electrical disturbances giving answers to the need of the manufacturers, utilities and electric energy customers.

\section{REFERENCES}

[1] L. A. Zadeh, "Fuzzy sets," Inform. Control, vol. 8, pp. 338353, 1965.

[2] E. H. Mamdani and S. Assilian, "An experiment in linguistic synthesis with a fuzzy logic controller," Int. J. Man-Mach. Stud., vol. 7, pp. 1-13, 1975.

[3] E.W. Gunther and H. Mehta, "A Survey of Distribution System power Quality - Preliminary Results", IEEE Transactions on Power Delivery, Vol. 10, No.1, pp. 322329, January 1995.

[4] K.Tanaka, An Introduction to Fuzzy Logic fro practical Applications, Springer-Verlag New York, Inc., New York, NY, USA, 1997.

[5] Mamdani, E.H. and S. Assilian, "An experiment in linguistic synthesis with a fuzzy logic controller," International Journal of Man-Machine Studies, Vol. 7, No. 1, pp. 1-13, 1975.

[6] Jang, J.-S. R. and C.-T. Sun, Neuro-Fuzzy and Soft Computing: AComputational Approach to Learning and Machine Intelligence, Prentice Hall, 1997.

[7] Sugeno, M., Industrial applications of fuzzy control, Elsevier Science Pub. Co., 1985

[8] "Fuzzy logic toolbox user's guide", The MathWorks Inc., 1999.

[8] Fuzzy logic in power system performability. Dumitrescu M, Munteanu T, Ulmeanu A P. Intelligent Systems, 2004. Proceedings, $20042^{\text {nd }}$ International IEEE conference. pages 326-330 vol1.

[9] A Fuzzy Logic application to represent Load sensitivity to voltage sags. Bonatto, B.D.; Niimura,T.; Dommel,H.W.; Hamonics and quality of power, 1998 , proceedings. $8^{\text {th }}$ International conference, Pages 60-64, vol1.

[10] Lighting protection of power systems using fuzzy logic techniques. Orille, A.L.; Bogarra, S.; Grau, M.A.; Iglesias, J.; Fuzzy systems, 2003.FUZZ'03. $12^{\text {th }}$ IEEE international conference, Volume: 2 